\title{
Genetics and Smoking
}

\author{
Anu Loukola • Jenni Hällfors • Tellervo Korhonen • \\ Jaakko Kaprio
}

Published online: 7 January 2014

(C) Springer International Publishing AG 2014

\begin{abstract}
Regular smoking is the major risk factor for cardiovascular disease and cancers, and thus is one of the most preventable causes of morbidity and mortality worldwide. Intake of nicotine, its central nervous system effects, and its metabolism are regulated by biological pathways; some of these are well known, but others are not. Genetic studies offer a method for developing insights into the genes contributing to those pathways. In recent years, large genome-wide association study (GWAS) meta-analyses have consistently revealed that the strongest genetic contribution to smokingrelated traits comes from variation in the nicotinic receptor subunit genes. Many other genes, including those coding for enzymes involved in nicotine metabolism, also have been implicated. However, the proportion of phenotypic variance explained by the identified genetic variants is very modest. This review intends to cover progress made in genetics and genetic epidemiology of smoking behavior in recent years, and focuses on studies revealing the nicotinic receptor gene cluster on chromosome $15 \mathrm{q} 25$. Evidence supporting the
\end{abstract}

A. Loukola $\cdot$ J. Hällfors · T. Korhonen · J. Kaprio $(\bowtie)$

Hjelt Institute, Department of Public Health, University of Helsinki, Mannerheimintie 172, P.O. Box 41, FI-00014 Helsinki, Finland

e-mail: jaakko.kaprio@helsinki.fi

A. Loukola

e-mail: anu.loukola@helsinki.fi

J. Hällfors

e-mail: jenni.hallfors@helsinki.fi

T. Korhonen

e-mail: tellervo.korhonen@helsinki.fi

J. Hällfors $\cdot$ J. Kaprio

Institute for Molecular Medicine Finland FIMM, University of

Helsinki, Tukholmankatu 8, P.O. Box 20, FI-00014 Helsinki, Finland

J. Kaprio

National Institute for Health and Welfare, Mannerheimintie 166, P.O. Box 30, FI-00271 Helsinki, Finland involvement of a novel pathway in the shared pathophysiology of nicotine dependence and schizophrenia is also briefly reviewed. A summary of the current knowledge on geneenvironment interactions involved in smoking behavior is included.

Keywords Tobacco $\cdot$ Nicotine $\cdot$ Nicotine metabolism · Addiction $\cdot$ Genes $\cdot$ Genome-wide association $\cdot$ Nicotinic receptors

\section{Introduction}

Smoking is a fast and efficient form of drug use, exposing smokers to multiple harmful components in tobacco. These cause the well-known consequences of smoking, which are extensive and cause disease in almost every organ and part of the body [1]. The largest public health burden arises from cancers (for example lung cancer), cardiovascular disease, chronic obstructive pulmonary disease (COPD), and a variety of mental disorders. Nicotine is the main addictive component in tobacco. Cigarette smokers control their nicotine levels via cigarette consumption, number and volume of puffs, and depth of inhalation [2]. During smoking, nicotine is distilled from burning tobacco, and when inhaled, is carried on tar droplets to the lungs. In the small airways and alveoli of the lung nicotine is rapidly absorbed, and is then distributed via the bloodstream, reaching the brain in 10-20 s [2, 3]. Nicotine binds to brain tissue with high affinity, especially in regular smokers whose binding capacity is increased as a result of functional up-regulation of nicotinic acetylcholine receptors (nAChRs) [4]. The rapid delivery of nicotine enables the smoker to titrate the dose to achieve the desired pharmacological effect, which further reinforces drug self-administration and facilitates the development of addiction [2]. 
Intake of nicotine, its central nervous system effects, and its metabolism are regulated by biological pathways; some of these are well known, but others are not. Genetic studies offer possible insights into the genes contributing to those pathways, via studying genetic variation by using different study designs. Family and twin studies have revealed a high degree of heritability of smoking and nicotine dependence $[5,6]$. In recent years, large genome-wide association study (GWAS) meta-analyses have revealed that the strongest genetic contribution for smoking-related traits comes from variation in the

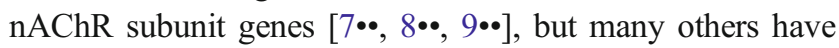
been implicated by candidate gene studies, small scale GWAS, and extensive animal studies. This review intends to cover progress made in several specific areas of the genetics and genetic epidemiology of smoking behavior and nicotine dependence in recent years.

\section{Genetic Findings Regarding Nicotinic Acetylcholine Receptors}

In the brain, nicotine binds to nAChRs, which are ligandgated cation channels that normally bind endogenous acetylcholine [10]. The binding of nicotine at the receptor bindingsite induces the release of a variety of neurotransmitter molecules, for example dopamine, serotonin, glutamate, and gamma aminobutyric acid (GABA) [11, 12]. Dopamine controls the reward pathway, and is thus a major contributor to the development of addiction [13]. Nicotine also increases the release of glutamate [14], which is believed to be involved in learning and memory by enhancing synaptic plasticity [11, 15]. Consequently, the pleasurable experience of smoking is created by learning and memory, reinforcing the addictive effects of nicotine. As described above, the inhalation of smoke particles from tobacco initiates a complex set of modifications in signaling cascades that probably have a strong pharmacological contribution to nicotine addiction.

Nicotinic receptors are broadly classified as muscle-type and neuronal-type on the basis of their primary expression sites. The mammalian nervous system is known to express twelve neuronal subunits, nine alpha $\left(\alpha_{2}-\alpha_{10}\right)$ and three beta subunits $\left(\beta_{2}-\beta_{4}\right)$, and five muscular subunits $(\alpha 1, \beta 1, \gamma, \delta$, and $\varepsilon)$. Nicotinic receptors are pentameric structures [16], and different combinations of subunits result in different receptor subtypes that vary in pharmacological properties, for example binding affinity, and distribution in the nervous system. The most widely expressed nAChR subtype in the human brain is composed of alpha 4 and beta 2 subunits, and it has a central function in the mediation of physiological effects of nicotine [17].

In 2010, large GWAS meta-analyses convincingly confirmed that the strongest genetic contribution to smokingrelated traits comes from variation in the $\mathrm{nAChR}$ subunit genes $[7 \bullet \bullet, 8 \bullet \bullet, 9 \bullet \bullet]$, as first revealed on a genome-wide significant level by Thorgeirsson et al. [18] in a study of over 13000 smokers from Iceland. The CHRNA5-CHRNA3CHRNB4 gene cluster on chromosome 15q25.1, encoding the alpha5, alpha3, and beta4 subunits, has provided the most prominent genetic evidence; first regarding amount smoked (cigarettes per day, CPD), and subsequently regarding other smoking-related phenotypes. Most GWAS meta-analyses have been conducted on populations of European ancestry. The signal from the $15 \mathrm{q} 25.1$ region has also been identified in African Americans [19], but not in the Asian population [20].

The $15 q 25.1$ locus contains a dense set of highly correlated single nucleotide polymorphisms (SNPs), and further examination of the region has revealed at least two distinct loci that contribute to heaviness of smoking [21•]. The most wellestablished locus within the $15 \mathrm{q} 25.1$ region is tagged by the functional SNP rs16969968 that causes an amino acid change (D398N) in the alpha5 subunit [22], and has been revealed to contribute to increased nicotine consumption by reducing the ability of $(\alpha 4 \beta 2) \alpha 5 \mathrm{nAChRs}$ to induce a normal inhibitory motivational signal intended to limit nicotine intake [23•]. The variant has a remarkably similar effect in all studied samples, even though the minor allele frequencies vary between populations $[24,25]$. In a recent replication study of a large and homogenous Finnish population sample, the estimated effect size for rs16969968 was 1.39 (odds ratio) for heavy smoking $(C P D>20)$ vs. light smoking $(C P D \leq 10)[26]$. The effect size of this SNP for continuous CPD was approximately one CPD for each minor allele, in agreement with the original GWAS report by Thorgeirsson et al. [18].

Several independent replications regarding a variety of smoking-related traits and diseases, including nicotine dependence, smoking amount, age of initiation, lung cancer, and COPD, have been reported on either rs16969968 or other highly correlated polymorphisms (e.g. rs1051730 located on CHRNA3) [27-33]. In addition, an age-associated relationship underlying the detected associations has been suggested [34•], with a stronger association in early-onset smokers.

Further investigation of this robust smoking-quantityassociated region has revealed novel findings relating to other phenotypes. For instance, association was detected between alcohol use and rs588765, an SNP believed to tag a third distinct locus contributing to smoking behavior [21•], in a large Finnish population-based sample [26]. The results provided a new direction for research on the CHRNA5-CHRNA3CHRNB4 gene cluster, and suggested that the effects of alcohol may be partially mediated via cholinergic receptors. Earlier, there were reports linking this variant to alcohol and cocaine dependence [35]. Another association was detected, in a large Norwegian sample, between the functional SNP rs16969968 and use of snus [28]. Snus is a moist, smokeless, nicotine-containing tobacco product, which delivers high 
quantities of nicotine, and has a very similar addiction potential to cigarettes [36].

Variation in another nAChR gene cluster on chromosome 8p11.21, which contains genes encoding the alpha6 and beta3 subunits (CHRNA6, CHRNB3), has genome-wide significant

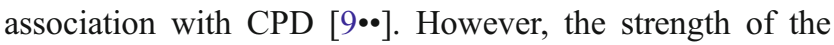
association is modest compared with those obtained for the CHRNA5-CHRNA3-CHRNB4 gene cluster. Independent studies have provided further evidence of association between CHRNB 3 and nicotine dependence, measured by the Fagerström test for nicotine dependence (FTND) [37], in multiple ethnic populations [38, 39].

Genome-wide association studies have provided a powerful tool for studying common variants in large samples. Despite the potential function of each nAChR gene in smoking behavior, GWAS have identified only a few subunits $(\alpha 5, \alpha 3, \beta 4, \alpha 6$, and $\beta 3)$. A meta-analysis of 15 genomewide linkage scans yielded a genome-wide significant linkage signal at 20q13.12-q13.32, a locus that contains CHRNA4, the gene encoding nAChR subunit alpha4 [40॰]. Re-sequencing of CHRNA4 and CHRNB4 has disclosed rare variants affecting inter-individual differences of nicotine dependence [41, 42]. For both genes, rare non-synonymous variants with protective effects against nicotine dependence were detected. Nextgeneration sequencing will probably enable discovery of more rare variants, explaining differences in smoking behavior and predisposition to smoking-related diseases.

Before the era of GWAS, candidate gene studies implied associations between smoking behavior and several genes, e.g. within the nicotinergic and dopaminergic pathways [43]. However, most of the findings lack consistent replication, which suggests either high type-I error (false positive signals) in these studies, inadequate power to detect genetic loci with small effect sizes, or population specificity of the detected associations.

\section{Neuregulin Signaling Pathway}

Many of the gene systems implicated in smoking behavior have pleiotropic effects across a variety of substance dependencies and other established co-morbidities of smoking, for example depression and schizophrenia, suggesting shared underlying pathophysiology. For example, variants in nAChR genes have been associated not only with smoking quantity and nicotine dependence, but also with alcohol and cocaine dependence [35]. Detected associations between schizophrenia and variants in CHRNA3 [44], CHRNA5 [45], and CHRNA7 [46] suggest a function for nAChRs in schizophrenia predisposition. In a recent GWAS combining five psychiatric disorders (schizophrenia, bipolar disorder, major depressive disorder, autism spectrum disorders, and attention deficit hyperactivity disorder), two calcium channel subunits,
$C A C N A 1 C$ and $C A C N B 2$, were identified [47]. It is plausible that genetic variation in basic systems may increase general susceptibility to neuropsychiatric disorders, and some combination of other genetic and non-genetic risk factors channels this risk into the development of specific disorders.

The co-morbidity between schizophrenia and nicotine dependence is well established, yet the underlying shared etiology is largely unknown. Most patients with schizophrenia smoke, and up to $75 \%$ of them are nicotine dependent [48]. Recently, the neuregulin signaling pathway (NSP) was suggested as a novel component of the shared genetic underpinnings of schizophrenia and nicotine dependence [49•, 50•]. Neuregulins are a family of signaling molecules that bind to receptor tyrosine kinases of the ErbB family to modulate neuronal migration and differentiation [51]. The ErbB4 receptor has an important function in regulating neurite outgrowth, axonal guidance, and synaptic signaling and plasticity [52]. The NSP consists of gene products encoded by at least 10 distinct genes. Three of those genes, Neuregulin 1 (NRG1), Neuregulin 3 (NRG3), and V-Erb-A Erythroblastic Leukemia Viral Oncogene Homolog 4 (Avian) (ERBB4), have been associated with schizophrenia predisposition and symptomatology [53-59]. Evidence from mouse models supports a function for at least two additional members, $B A C E 1$ and $A P H 1 B$, in schizophrenia [60, 61].

A recent GWAS on Finnish twins revealed convergent evidence for an association between DSM-IV (Diagnostic and statistical manual of mental disorders, 4th edition) [62] nicotine dependence and ERBB4, suggesting involvement of the NSP in nicotine dependence [49॰]. This finding was supported by behavioral mouse models revealing abolishment of withdrawal-induced anxiety both in mice with a knock-down mutation in $\mathrm{Nrg} 3$ and in mice treated with an ErbB4 inhibitor, suggesting that the NSP is essential to the anxiety effects of nicotine withdrawal [50•]. NRG3 variants were revealed to be associated with smoking cessation success in a clinical trial [50 ]. Because it has been suggested that multiple variants aggregating in the NSP may be necessary to predispose patients to schizophrenia [63], scrutiny of other members within the NSP may reveal a further shared genetic predisposition for schizophrenia and nicotine dependence.

\section{Nicotine Metabolism}

Nicotine metabolism involves multiple steps and several enzymatic pathways [2]. Only approximately $10 \%$ of absorbed nicotine is excreted to urine unchanged. Up to $80 \%$ of nicotine is converted to cotinine in a two-step process: the first step is mediated by the cytochrome P450 system, mainly by CYP2A6 (cytochrome P450, family 2, subfamily A, polypeptide 6); and the second step is catalyzed by a cytoplasmic aldehyde oxidase [2]. Cotinine is further metabolized into a 
variety of compounds, by far the most prominent being the conversion of cotinine to 3-hydroxycotinine, performed exclusively by CYP2A6. The remaining $10 \%$ of nicotine is metabolized through oxidation, glucuronidation, or methylation before excretion [2].

Inter-individual rates of nicotine metabolism vary substantially. CYP2A6 encodes the main metabolic enzyme for nicotine [64], accounting for approximately $80 \%$ of hepatic nicotine oxidation. To date, over 60 distinct $C Y P 2 A 6$ alleles have been identified (http://www.cypalleles.ki.se/cyp2a6.htm), including SNPs, duplications, deletions, and conversions. CYP2A6 alleles have been phenotypically grouped as slow, intermediate, and normal metabolizers, with significant differences in allele frequencies among ethnic groups [65]. Individuals who carry null or reduced activity $C Y P 2 A 6$ alleles are more probably non-smokers, smoke fewer cigarettes per day, are less likely to progress to nicotine dependence, are less dependent on nicotine, may have an easier time quitting smoking, and have a lower risk of lung cancer $[66,67]$.

Twin studies suggest an important genetic contribution to total clearance of nicotine (nicotine $\rightarrow$ cotinine $\rightarrow 3$ hydroxycotinine), with heritability estimates of 50-68\% [68]. Cotinine is a relatively stable compound, with a halflife of 15-20 h [69], and can be used to distinguish smokers from non-smokers and as a biomarker of nicotine intake. In individuals with slower CYP2A6 activity, however, cotinine accumulates [70]; therefore, cotinine levels may not reliably reflect tobacco exposure. The ratio of 3-hydroxycotinine/cotinine, referred to as the nicotine metabolite ratio (NMR), reflects both genetic variation in nicotine-metabolizing enzymes and environmental factors (e.g. estrogen levels and body mass index) [69], and can be used as a proxy for the rate of nicotine clearance [71]. The NMR remains fairly constant over time in regular smokers, and is not dependent on the time of last nicotine dosing.

CYP2B6 (cytochrome P450, family 2, subfamily B, polypeptide 6) is the second most active $\mathrm{P} 450$ enzyme involved in nicotine oxidation, and has approximately $10 \%$ of the catalytic efficiency of CYP2A6. Whereas CYP2A6 is expressed primarily in the liver, CYP2B6 is expressed at higher levels in the brain, possibly accounting for localized metabolism of nicotine in the brains of human smokers [72]. At least two additional P450 enzymes, CYP2D6 and CYP2E1, have some activity toward nicotine [2].

Cytochrome P450 drug-metabolizing enzymes are rarely positive in GWAS, because the allele frequencies of the functional variants are low in most populations [2]. However, a recent very large GWAS meta-analysis revealed associations between smoking quantity and variants in $C Y P 2 A 6$ and $C Y P 2 B 6[9 \cdot \bullet]$. The associating variant in $C Y P 2 A 6$ is in linkage disequilibrium with the reduced-activity allele [9••]. However, when disentangling the GWAS results, genetic complexities should be considered. Recently, a variant in EGLN2 (Homo sapiens egl nine homolog 2 (C. elegans), a gene located adjacent to CYP2A6 on chromosome $19 \mathrm{q} 13$, was revealed to independently associate with CPD and breath carbon monoxide, a phenotype associated with cigarette consumption and relevant to hypoxia [73]. It is plausible that genes within the $19 \mathrm{q} 13$ locus other than $C Y P 2 A 6$ also affect smoking behavior, via mechanisms unrelated to nicotine metabolism. Combined effects of CYP2A6 and CHRNA5 on smoking behavior have been reported $[74,75]$. Within most Caucasian populations, with up to $90 \%$ of individuals being fast metabolizers, a small fraction of variance in inter-individual differences in nicotine metabolism is accounted for by known allelic variants affecting CYP2A6 activity. Other contributing factors, for example regulators of CYP2A6 action, functional variants in other genes, gene-gene interactions, and gene-environment interactions, are bound to exist.

Major challenges in the genetic studies of smoking behavior include phenotype heterogeneity and lack of consistent outcome measurements. It is probable that the phenotypic definitions used to date, for example self-reported cigarettes per day, do not accurately reflect nicotine intake, as revealed by the finding that the CHRNA5 variant accounts for five times more variance in cotinine levels than in smoking quantity $[76,77]$. In an interim GWAS meta-analysis of cotinine levels, a sample of approximately 2000 individuals revealed association with the CHRNA5-A3-B4 gene cluster [78], with $P$ values exceeding genome-wide significance, and effect sizes comparable to those obtained for smoking quantity by a large $(N=74053)$ GWAS meta-analysis [7••]. Consideration of phenotype quality and precision is proving more beneficial than recruiting increasing numbers of subjects with crude phenotypes [77], revealing the utility of measurable biomarkers in the genetic analysis of smoking behavior.

\section{Gene-Environment Interactions}

It is important to recognize that genes alone do not determine phenotypes: environmental factors can significantly regulate the expression of an individual's genetic predisposition [6]. Twin and family studies have also been used to define the function of non-genetic factors, which is possible through the control of confounding genetic factors in genetically informative data sets. The standard models used to estimate heritability from twin and family studies and to evaluate findings from GWAS assume that the effects of genes and environments are independent of each other. However, heritability may be overestimated if gene-environment $(\mathrm{G} \times \mathrm{E})$ interactions are present. Despite expectations of substantial $\mathrm{G} \times \mathrm{E}$ correlations and interactions, caused by influences on smoking initiation from environmental factors shared within families and from extra-familial environmental factors shared with peers and birth cohorts, such effects have not been widely studied. In a 
$\mathrm{G} \times \mathrm{E}$ interaction study conducted on the Finnish FinnTwin12 cohort, genetic effects on adolescent smoking decreased and common environmental influences increased at higher levels of parental monitoring [79]. Similarly, religiousness has been reported to significantly attenuate the effect of genetic variance on smoking initiation [80]. Environment interaction analyses of CHRNA5 have revealed that both parental monitoring and peer influence (smoking) modify the association between nicotine dependence and rs 16969968 [81, 82]. Furthermore, the rs 16969968 risk allele contributes a stronger genetic risk of heavy smoking in early-onset smokers (age at onset $\leq 16$ years) than in late-onset smokers [34•]. More studies of $\mathrm{G} \times \mathrm{E}$ interactions may help determine why heritability estimates for smoking behaviors vary so greatly and why the search for predisposing genes has not been particularly successful to date. Some $\mathrm{G} \times \mathrm{E}$ interactions probably reflect epigenetic mechanisms, for example DNA methylation. Epigenetic processes react to external factors, and therefore provide a crucial mechanism by which environment can affect gene expression and hence phenotype. This is a topic of active research, with major breakthroughs expected in the near future; however, findings in epigenetics are outside the scope of this chapter.

\section{Conclusions}

The progress made in recent years in understanding the genetic epidemiology of non-communicable diseases, and of many normal human and animal traits, has deepened our understanding of the underlying intricate genetic architecture, while providing insights into the interplay of genes and environment in normal and abnormal development of organisms. Projected deaths from tobacco-induced diseases are estimated to reach hundreds of millions this century unless prevention and treatment can be made much more effective. Using genetics to improve our knowledge of the neurobiology and neuropathology of nicotine and other tobacco components is essential in building the knowledge base necessary for action.

Mendelian randomization (MR) can be used to scrutinize the multiple reported associations of smoking with a variety of diseases [83]. Although many are causal, resulting from the extreme toxicity of cigarettes and other tobacco products, some may result from confounding. The functional variant D398N (rs16969968) in CHRNA5 has a strong effect on smoking behavior and thus fulfils one of the necessary prerequisites for MR analyses. An ongoing large-scale MR metaanalysis conducted by the CARTA (Causal Analysis Research in Tobacco and Alcohol, PI professor Marcus Munafò, University of Bristol, UK) consortium targets rs16969968 to detect evidence for causal effects of smoking quantity on several independent outcomes, including smoking cessation, obesity and regional adiposity, income, vitamin D levels, lipids, blood pressure, and depression (http://www.bris.ac. uk/expsych/research/brain/targ/research/interests/).

The search for more genes continues, and is empowered by increasing GWAS sample sizes, by extending analyses to exome and whole genome sequence data, and by improving phenotypes. The D398N variant accounts for only approximately $1 \%$ of variation in $\mathrm{CPD}$, but almost $5 \%$ of variation in cotinine levels, as reviewed above $[76,77]$. Thus, it should be easier to detect smoking-related genetic effects by using a biomarker of exposure (cotinine) rather than a crude measure of intake (CPD). On the basis of this assumption, a cotinine GWAS meta-analysis is in progress and results will be reported in 2014. At the moment new cohorts are not being accepted for inclusion, but for more information please contact Dr Jennifer Ware, University of Bristol. For dependence phenotypes, a GWAS consortium for FTND is coordinated by Dr Sam Chen, Virginia Commonwealth University; and for DSM-IV diagnoses, nicotine dependence is being analyzed within the framework of the Psychiatric Genomics Consortium (www.pgc.unc.edu). A genome-wide metaanalysis initiative targeting exomic variants has been established by the GWAS \& Sequencing Consortium of Alcohol and Nicotine use (GSCAN), coordinated by Dr Scott Vrieze at the University of Michigan (http://gscan.sph. umich.edu/). Although not an exhaustive list of the collaborative efforts needed to make further progress, this brief summary is illustrative of the willingness of the nicotine-dependence genetics community to work together.

Overall, next-generation sequencing will probably provide means to uncover more rare variants explaining differences in smoking-related behavior and predisposition to smokingrelated diseases. Be they common or rare variants, identifying genetic loci linked to smoking behaviors is merely the first step in the discovery process. Many associations have not been properly evaluated for their functional relevance or for their public health effect. We can look forward to many years of exciting progress in this area.

Acknowledgments This work was supported in part by the Academy of Finland Center of Excellence in Complex Disease Genetics (grant numbers 213506, 129680 to Jaakko Kaprio), Helsinki Biomedical Graduate Program, HBGP (to Jenni Hällfors), the Academy of Finland (265240, 263278, 264146, 141054 to Jaakko Kaprio), the Sigrid Juselius Foundation (to Jaakko Kaprio), NIH grant DA12854 (to Pamela A.F. Madden), and ENGAGE - European Network for Genetic and Genomic Epidemiology, FP7-HEALTH-F4-2007, grant agreement number 201413. The FIMM Technology Center and the Welcome Trust Sanger Institute are acknowledged for genome-wide genotyping in the Finnish samples.

\section{Compliance with Ethics Guidelines}

Conflict of Interest Jaakko Kaprio has consulted for Pfizer on nicotine dependence in 2011-2013, and for ERAB on alcohol drinking in 2011. Tellervo Korhonen has consulted for Pfizer on tobacco dependence treatment in 2011-2013. Dr Korhonen also has received grants from the 
Juho Vainio Foundation and payment for lectures including service on speakers' bureaus from Turku University Hospital. Anu Loukola and Jenni Hällfors declare that they have no conflict of interest.

Human and Animal Rights and Informed Consent This article does not contain any studies with human or animal subjects performed by any of the authors.

\section{References}

Papers of particular interest, published recently, have been highlighted as:

- Of importance

•• Of major importance

1. USDHHS. How Tobacco Smoke Causes Disease: The Biology and Behavioral Basis for Smoking-Attributable Disease: A Report of the Surgeon General. Atlanta, GA. U.S. Department of Health and Human Services, Centers for Disease Control and Prevention, National Center for Chronic Disease Prevention and Health Promotion, Office on Smoking and Health; 2010.

2. Hukkanen J, Jacob 3rd P, Benowitz NL. Metabolism and disposition kinetics of nicotine. Pharmacol Rev. 2005;57:79-115.

3. Berridge MS, Apana SM, Nagano KK, Berridge CE, Leisure GP, Boswell MV. Smoking produces rapid rise of [11C]nicotine in human brain. Psychopharmacology (Berl). 2010;209:383-94.

4. Buisson B, Bertrand D. Nicotine addiction: the possible role of functional upregulation. Trends Pharmacol Sci. 2002;23:130-6.

5. Lessov-Schlaggar CN, Pergadia ML, Khroyan TV, Swan GE. Genetics of nicotine dependence and pharmacotherapy. Biochem Pharmacol. 2008;75:178-95.

6. Rose JE, Broms U, Korhonen T, Dick DM, Kaprio J. Genetics of smoking behavior. In: Kim YK, editor. Handbook of behavior genetics. New York: Springer; 2009. p. 411-32.

7.• Tobacco and Genetics Consortium. Genome-wide meta-analyses identify multiple loci associated with smoking behavior. Nat Genet. 2010;42:441-7. Papers 7-9, published back-to-back in Nature Genetics in 2010, jointly looked at four smoking behavior phenotypes in a GWAS meta-analysis comprising approximately 1400000 subjects.

8.• Liu JZ, Tozzi F, Waterworth DM, Pillai SG, Muglia P, Middleton L, et al. Meta-analysis and imputation refines the association of $15 \mathrm{q} 25$ with smoking quantity. Nat Genet. 2010;42:436-40. Papers 7-9, published back-to-back in Nature Genetics in 2010, jointly looked at four smoking behavior phenotypes in a GWAS meta-analysis comprising approximately 1400000 subjects.

9.• Thorgeirsson TE, Gudbjartsson DF, Surakka I, Vink JM, Amin N, Geller F, et al. Sequence variants at CHRNB3-CHRNA6 and CYP2A6 affect smoking behavior. Nat Genet. 2010;42:448-53. Papers 7-9, published back-to-back in Nature Genetics in 2010, jointly looked at four smoking behavior phenotypes in a GWAS meta-analysis comprising approximately 1400000 subjects.

10. Miyazawa A, Fujiyoshi Y, Unwin N. Structure and gating mechanism of the acetylcholine receptor pore. Nature. 2003;423:949-55.

11. Dajas-Bailador F, Wonnacott S. Nicotinic acetylcholine receptors and the regulation of neuronal signalling. Trends Pharmacol Sci. 2004;25:317-24.

12. Wonnacott S. Presynaptic nicotinic ACh receptors. Trends Neurosci. 1997;20:92-8.

13. Nestler EJ. Is there a common molecular pathway for addiction? Nat Neurosci. 2005;8:1445-9.
14. Schilstrom B, Fagerquist MV, Zhang X, Hertel P, Panagis G, Nomikos GG, et al. Putative role of presynaptic alpha7* nicotinic receptors in nicotine stimulated increases of extracellular levels of glutamate and aspartate in the ventral tegmental area. Synapse. 2000;38:375-83.

15. Riedel G, Platt B, Micheau J. Glutamate receptor function in learning and memory. Behav Brain Res. 2003;140:1-47.

16. Cooper E, Couturier S, Ballivet M. Pentameric structure and subunit stoichiometry of a neuronal nicotinic acetylcholine receptor. Nature. 1991;350:235-8.

17. Collins AC, Salminen O, Marks MJ, Whiteaker P, Grady SR. The road to discovery of neuronal nicotinic cholinergic receptor subtypes. Handb Exp Pharmacol. 2009;192:85-112.

18. Thorgeirsson TE, Geller F, Sulem P, Rafnar T, Wiste A, Magnusson $\mathrm{KP}$, et al. A variant associated with nicotine dependence, lung cancer and peripheral arterial disease. Nature. 2008;452:638-42.

19. David SP, Hamidovic A, Chen GK, Bergen AW, Wessel J, Kasberger JL, et al. Genome-wide meta-analyses of smoking behaviors in African Americans. Transl Psychiatry. 2012;2:e119.

20. Yoon D, Kim YJ, Cui WY, Van der Vaart A, Cho YS, Lee JY, et al. Large-scale genome-wide association study of Asian population reveals genetic factors in FRMD4A and other loci influencing smoking initiation and nicotine dependence. Hum Genet. 2012;131:1009-21.

21. Saccone NL, Culverhouse RC, Schwantes-An TH, Cannon DS, Chen X, Cichon S, et al. Multiple independent loci at chromosome 15 q25.1 affect smoking quantity: a meta-analysis and comparison with lung cancer and COPD. PLoS Genet. 2010;6:e1001053. In this paper the authors diligently scrutinized the 15q25 smoking locus, and dissected several independent loci contributing to smoking behavior, suggesting a high level of genetic complexities within this locus.

22. Bierut LJ. Genetic vulnerability and susceptibility to substance dependence. Neuron. 2011;69(4):618-27.

23. Fowler CD, Lu Q, Johnson PM, Marks MJ, Kenny PJ. Habenular alpha5 nicotinic receptor subunit signalling controls nicotine intake. Nature. 2011;471:597-601. This sophisticated paper reveals that, at least in rodents, CHRNA5 is crucial in inducing an inhibitory motivational signal that acts to limit nicotine intake.

24. Saccone NL, Wang JC, Breslau N, Johnson EO, Hatsukami D, Saccone SF, et al. The CHRNA5-CHRNA3-CHRNB4 nicotinic receptor subunit gene cluster affects risk for nicotine dependence in African-Americans and in European-Americans. Cancer Res. 2009;69:6848-56.

25. Li MD, Yoon D, Lee JY, Han BG, Niu T, Payne TJ, et al. Associations of variants in CHRNA5/A3/B4 gene cluster with smoking behaviors in a Korean population. PLoS One. 2010;5: e12183.

26. Hallfors J, Loukola A, Pitkaniemi J, Broms U, Mannisto S, Salomaa V, et al. Scrutiny of the CHRNA5-CHRNA3-CHRNB4 smoking behavior locus reveals a novel association with alcohol use in a Finnish population based study. Int J Mol Epidemiol Genet. 2013;4:109-19.

27. Broms U, Wedenoja J, Largeau MR, Korhonen T, Pitkaniemi J, Keskitalo-Vuokko K, et al. Analysis of detailed phenotype profiles reveals CHRNA-CHRNA3-CHRNB4 gene cluster association with several nicotine dependence traits. Nicotine Tob Res. 2012;14:720 33. doi:10.1093/ntr/ntr283.

28. Gabrielsen ME, Romundstad P, Langhammer A, Krokan HE, Skorpen F. Association between a $15 \mathrm{q} 25$ gene variant, nicotine-related habits, lung cancer and COPD among 56307 individuals from the HUNT study in Norway. Eur J Hum Genet. 2013;21:1293-9.

29. Lips EH, Gaborieau V, McKay JD, Chabrier A, Hung RJ, Boffetta $\mathrm{P}$, et al. Association between a 15q25 gene variant, smoking quantity and tobacco-related cancers among 17000 individuals. Int J Epidemiol. 2010;39:563-77. 
30. Walsh KM, Amos CI, Wenzlaff AS, Gorlov IP, Sison JD, Wu X, et al. Association study of nicotinic acetylcholine receptor genes identifies a novel lung cancer susceptibility locus near CHRNA1 in African-Americans. Oncotarget. 2012;3:1428-38.

31. Walsh KM, Gorlov IP, Hansen HM, Wu X, Spitz MR, Zhang H, et al. Fine-mapping of the 5p15.33, 6p22.1-p21.31, and 15q25.1 regions identifies functional and histology-specific lung cancer susceptibility loci in African-Americans. Cancer Epidemiol Biomarkers Prev. 2013;22:251-60.

32. Kapoor M, Wang JC, Bertelsen S, Bucholz K, Budde JP, Hinrichs $\mathrm{A}$, et al. Variants located upstream of CHRNB4 on chromosome $15 \mathrm{q} 25.1$ are associated with age at onset of daily smoking and habitual smoking. PLoS One. 2012;7:e33513.

33. Stephens SH, Hartz SM, Hoft NR, Saccone NL, Corley RC, Hewitt JK, et al. Distinct loci in the CHRNA5/CHRNA3/CHRNB4 gene cluster are associated with onset of regular smoking. Genet Epidemiol. 2013;37:846-59.

34. Hartz SM, Short SE, Saccone NL, Culverhouse R, Chen L, Schwantes-An TH, et al. Increased genetic vulnerability to smoking at CHRNA5 in early-onset smokers. Arch Gen Psychiatry. 2012;69:854-60. A large meta-analysis presenting evidence for a gene by environment $(G \times E)$ interaction at the $15 q 25$ locus.

35. Sherva R, Kranzler HR, Yu Y, Logue MW, Poling J, Arias AJ, et al. Variation in nicotinic acetylcholine receptor genes is associated with multiple substance dependence phenotypes. Neuropsychopharmacology. 2010;35:1921-31.

36. Foulds J, Ramstrom L, Burke M, Fagerström K. Effect of smokeless tobacco (snus) on smoking and public health in Sweden. Tob Control. 2003;12:349-59.

37. Heatherton TF, Kozlowski LT, Frecker RC, Fagerström KO. The fagerström test for nicotine dependence: a revision of the fagerström tolerance questionnaire. Br J Addict. 1991;86:1119-27.

38. Rice JP, Hartz SM, Agrawal A, Almasy L, Bennett S, Breslau N, et al. CHRNB3 is more strongly associated with fagerström test for cigarette dependence-based nicotine dependence than cigarettes per day: phenotype definition changes genome-wide association studies results. Addiction. 2012;107:2019-28.

39. Cui WY, Wang S, Yang J, Yi SG, Yoon D, Kim YJ, et al. Significant association of CHRNB3 variants with nicotine dependence in multiple ethnic populations. Mol Psychiatry. 2013;18:1149-51.

40. Han S, Gelernter J, Luo X, Yang BZ. Meta-analysis of 15 genomewide linkage scans of smoking behavior. Biol Psychiatry. 2010;67: 12-9. This paper summarizes the linkage analysis literature, which may be of relevance when searching for rare variants in families.

41. Xie P, Kranzler HR, Krauthammer M, Cosgrove KP, Oslin D, Anton RF, et al. Rare nonsynonymous variants in alpha-4 nicotinic acetylcholine receptor gene protect against nicotine dependence. Biol Psychiatry. 2011;70:528-36.

42. Haller G, Druley T, Vallania FL, Mitra RD, Li P, Akk G, et al. Rare missense variants in CHRNB4 are associated with reduced risk of nicotine dependence. Hum Mol Genet. 2012;21:647-55.

43. Wang J, Li MD. Common and unique biological pathways associated with smoking initiation/progression, nicotine dependence, and smoking cessation. Neuropsychopharmacology. 2010;35:702-19.

44. Petrovsky N, Quednow BB, Ettinger U, Schmechtig A, Mossner R, Collier DA, et al. Sensorimotor gating is associated with CHRNA3 polymorphisms in schizophrenia and healthy volunteers. Neuropsychopharmacology. 2010;35:1429-39.

45. Hong LE, Yang X, Wonodi I, Hodgkinson CA, Goldman D, Stine OC, et al. A CHRNA5 allele related to nicotine addiction and schizophrenia. Genes Brain Behav. 2011;10:530-5.

46. Bakanidze G, Roinishvili M, Chkonia E, Kitzrow W, Richter S, Neumann K, et al. Association of the nicotinic receptor alpha7 subunit gene (CHRNA7) with schizophrenia and visual backward masking. Front Psychiatry. 2013;4:133.
47. Cross-Disorder Group of the Psychiatric Genomics Consortium, Genetic Risk Outcome of Psychosis (GROPU) Consortium. Identification of risk loci with shared effects on five major psychiatric disorders: a genome-wide analysis. The Lancet. 2013;381: 1371-79.

48. Patkar AA, Gopalakrishnan R, Lundy A, Leone FT, Certa KM, Weinstein SP. Relationship between tobacco smoking and positive and negative symptoms in schizophrenia. J Nerv Ment Dis. 2002;190:604-10

49. Loukola A, Wedenoja J, Keskitalo-Vuokko K, Broms U, Korhonen T, Ripatti S, et al. Genome-wide association study on detailed profiles of smoking behavior and nicotine dependence in a twin sample. Mol Psychiatry. 2013. doi:10.1038/mp.2013.72. This is the first paper to present data supporting the involvement of the neuregulin signaling pathway in nicotine dependence. The association between nicotine dependence and a neuregulin receptor, ERBB4, is supported by convergent evidence from linkage studies and by replication in an independent sample. Future support comes from behavioral mouse models (see Ref. [50], below).

50. Turner JR, Ray R, Lee B, Everett L, Xiang J, Jepson C, et al. Evidence from mouse and man for a role of neuregulin 3 in nicotine dependence. Mol Psychiatry. 2013. doi:10.1038/mp.2013.104. This paper nicely demonstrates that both ErbB4 and NRG3 (Neuregulin 3) expression increases during nicotine exposure and withdrawal in a mouse model. Further, withdrawal-induced anxiety is abolished both in mice with a knock-down mutation in Nrg3, and in mice treated with an ErbB4 inhibitor, suggesting that the neuregulin signaling pathway is essential in the anxiety effects of nicotine withdrawal. The authors also show that NRG3 SNPs associate with smoking cessation success in a clinical trial.

51. Falls DL. Neuregulins: functions, forms, and signaling strategies. Exp Cell Res. 2003;284:14-30.

52. Mei L, Xiong WC. Neuregulin 1 in neural development, synaptic plasticity and schizophrenia. Nat Rev Neurosci. 2008;9:437-52.

53. Stefansson H, Sigurdsson E, Steinthorsdottir V, Bjornsdottir S, Sigmundsson T, Ghosh S, et al. Neuregulin 1 and susceptibility to schizophrenia. Am J Hum Genet. 2002;71:877-92.

54. Stefansson H, Sarginson J, Kong A, Yates P, Steinthorsdottir V, Gudfinnsson E, et al. Association of neuregulin 1 with schizophrenia confirmed in a Scottish population. Am J Hum Genet. 2003;72: 83-7.

55. Harrison PJ, Law AJ. Neuregulin 1 and schizophrenia: genetics, gene expression, and neurobiology. Biol Psychiatry. 2006;60:13240.

56. Chen PL, Avramopoulos D, Lasseter VK, McGrath JA, Fallin MD, Liang KY, et al. Fine mapping on chromosome 10q22-q23 implicates Neuregulin 3 in schizophrenia. Am J Hum Genet. 2009;84: 21-34.

57. Silberberg G, Darvasi A, Pinkas-Kramarski R, Navon R. The involvement of ErbB4 with schizophrenia: association and expression studies. Am J Med Genet B Neuropsychiatr Genet. 2006;141B:142-8.

58. Norton N, Moskvina V, Morris DW, Bray NJ, Zammit S, Williams $\mathrm{NM}$, et al. Evidence that interaction between neuregulin 1 and its receptor erbB4 increases susceptibility to schizophrenia. Am J Med Genet B Neuropsychiatr Genet. 2006;141B:96-101.

59. Law AJ, Kleinman JE, Weinberger DR, Weickert CS. Diseaseassociated intronic variants in the ErbB4 gene are related to altered ErbB4 splice-variant expression in the brain in schizophrenia. Hum Mol Genet. 2007;16:129-41.

60. Savonenko AV, Melnikova T, Laird FM, Stewart KA, Price DL, Wong PC. Alteration of BACE1-dependent NRG1/ErbB4 signaling and schizophrenia-like phenotypes in BACE1-null mice. Proc Natl Acad Sci U S A. 2008;105:5585-90.

61. Dejaegere T, Serneels L, Schafer MK, Van Biervliet J, Horre K, Depboylu C, et al. Deficiency of Aph1B/C-gamma-secretase 
disturbs Nrg1 cleavage and sensorimotor gating that can be reversed with antipsychotic treatment. Proc Natl Acad Sci U S A. 2008; 105:9775-80.

62. Diagnostic and statistical manual of mental disorders: DSM-IV (4th edition). American Psychiatric Association: Washington, 1994.

63. Hatzimanolis A, McGrath JA, Wang R, Li T, Wong PC, Nestadt G, et al. Multiple variants aggregate in the neuregulin signaling pathway in a subset of schizophrenia patients. Transl Psychiatry. 2013;3:e264

64. Messina ES, Tyndale RF, Sellers EM. A major role for CYP2A6 in nicotine C-oxidation by human liver microsomes. J Pharmacol Exp Ther. 1997;282:1608-14.

65. Mwenifumbo JC, Tyndale RF. Genetic variability in CYP2A6 and the pharmacokinetics of nicotine. Pharmacogenomics. 2007;8: 1385-402.

66. Ho MK, Tyndale RF. Overview of the pharmacogenomics of cigarette smoking. Pharmacogenomics J. 2007;7:81-98.

67. Gold AB, Lerman C. Pharmacogenetics of smoking cessation: role of nicotine target and metabolism genes. Hum Genet 2012.

68. Swan GE, Lessov-Schlaggar CN, Bergen AW, He Y, Tyndale RF, Benowitz NL. Genetic and environmental influences on the ratio of 3 'hydroxycotinine to cotinine in plasma and urine. Pharmacogenet Genomics. 2009;19:388-98.

69. Benowitz NL, Hukkanen J, Jacob 3rd P. Nicotine chemistry, metabolism, kinetics and biomarkers. Handb Exp Pharmacol. 2009;192:29-60.

70. Zhu AZ, Renner CC, Hatsukami DK, Swan GE, Lerman C, Benowitz NL, et al. The ability of plasma cotinine to predict nicotine and carcinogen exposure is altered by differences in CYP2A6: the influence of genetics, race, and sex. Cancer Epidemiol Biomarkers Prev. 2013;22:708-18.

71. Dempsey D, Tutka P, Jacob 3rd P, Allen F, Schoedel K, Tyndale RF, et al. Nicotine metabolite ratio as an index of cytochrome P450 2A6 metabolic activity. Clin Pharmacol Ther. 2004;76:64-72.

72. Miksys S, Lerman C, Shields PG, Mash DC, Tyndale RF. Smoking, alcoholism and genetic polymorphisms alter CYP2B6 levels in human brain. Neuropharmacology. 2003;45:122-32.

73. Bloom AJ, Baker TB, Chen LS, Breslau N, Hatsukami D, Bierut LJ, et al. Variants in two adjacent genes, EGLN2 and CYP2A6, influence smoking behavior related to disease risk via different mechanisms. Hum Mol Genet 2013.

74. Chen LS, Bloom AJ, Baker TB, Smith SS, Piper ME, Martinez M, et al. Pharmacotherapy effects on smoking cessation vary with nicotine metabolism gene (CYP2A6). Addiction. 2013. doi:10. 1111/add. 12353.

75. Wassenaar CA, Dong Q, Wei Q, Amos CI, Spitz MR, Tyndale RF. Relationship between CYP2A6 and CHRNA5-CHRNA3CHRNB4 variation and smoking behaviors and lung cancer risk. J Natl Cancer Inst. 2011;103:1342-6.

76. Keskitalo K, Broms U, Heliovaara M, Ripatti S, Surakka I, Perola $\mathrm{M}$, et al. Association of serum cotinine level with a cluster of three nicotinic acetylcholine receptor genes (CHRNA3/CHRNA5/ CHRNB4) on chromosome 15. Hum Mol Genet. 2009;18:4007-12.

77. Munafò MR, Timofeeva MN, Morris RW, Prieto-Merino D, Sattar $\mathrm{N}$, Brennan P, et al. Association between genetic variants on chromosome $15 \mathrm{q} 25$ locus and objective measures of tobacco exposure. J Natl Cancer Inst. 2012;104:740-8.

78. Ware J, Munafò M. The genetic basis of heaviness of smoking: Results from a genome-wide meta-analysis. Boston: SRNT Annual Meeting; 2013.

79. Dick DM, Viken R, Purcell S, Kaprio J, Pulkkinen L, Rose RJ. Parental monitoring moderates the importance of genetic and environmental influences on adolescent smoking. J Abnorm Psychol. 2007;116:213-8.

80. Timberlake DS, Rhee SH, Haberstick BC, Hopfer C, Ehringer M, Lessem JM, et al. The moderating effects of religiosity on the genetic and environmental determinants of smoking initiation. Nicotine Tob Res. 2006;8:123-33.

81. Chen LS, Johnson EO, Breslau N, Hatsukami D, Saccone NL, Grucza RA, et al. Interplay of genetic risk factors and parent monitoring in risk for nicotine dependence. Addiction. 2009;104: 1731-40.

82. Johnson EO, Chen LS, Breslau N, Hatsukami D, Robbins T, Saccone NL, et al. Peer smoking and the nicotinic receptor genes: an examination of genetic and environmental risks for nicotine dependence. Addiction. 2010;105:2014-22.

83. Sheehan NA, Didelez V, Burton PR, Tobin MD. Mendelian randomisation and causal inference in observational epidemiology. PLoS Med. 2008;5:e177. 